\title{
"The Changing Role of Directors of University Libraries": Introduction to a Reprint of a CERL Classic
}

When Arthur McAnally and Robert Downs wrote their essay they were concerned about the "increasing number of incidents . . . which indicated that all was not well in the library directors' world." They cited a dramatic turnover among directors of Big Ten universities in 1971-72. At present, there are over fifteen vacant directorships among ARL libraries.

A generation has passed, but much has remained the same. The pressures described by the authors are as apparent now as when the article was first submitted for publication. After my first reading, I knew their essay would be an important contribution to our professional literature, but little did I realize how important.

The pressures McAnally and Downs identified have remained at the forefront and several have grown in intensity. Disciplines and their literatures have become more specialized, and this specialization has contributed to the continued rise in the cost of books and journals. And, yes, the information explosion is alive and well. Libraries are still plagued by hard times, and technology has accelerated organizational change and added a new element of instability.

In some ways, the environment has changed as well. The explosive growth in higher education enrollments has leveled out at most institutions. Unions are still present on some campuses, but their influence has not grown as the authors felt might occur. The current internal sources of pressure have not changed much: aca- demic administrators who know much about libraries are still rare-libraries are still seen as financial bottomless pits; staff who seek ever greater roles in decision making still agitate; and faculty who are concerned about collections and services to support their programs still lobby.

The authors felt that libraries were less able to meet needs than they had been in the 1960 s, and that changing patterns of instruction and research were also adding new stresses to the organizational structure of university libraries. These pressures continue to mount as new technological tools make it possible for users to consult libraries and catalogs without physically visiting the library.

The advice offered by McAnally and Downs is as sound and fresh as the day it was written. We need to plan better, budget more effectively, be more innovative in organizing library services, and finally, accept the reality that no library can stand on its own bottom. The rhetoric of resource sharing and cooperation still plays well, but the reality of actual programs has not progressed much further than that of the world inhabited by the authors.

The greatest change that has occurred in the last fifteen years can be found in the final paragraphs of the essay under the heading "Qualities of a Model Director." The authors write, "The director must be more flexible and adaptable; the old certainties are being questioned or are gone, and the university library will continue to 
undergo changes. $\mathrm{He}$ must be willing to accept change as a way of life, and be open-minded about alternatives"' (emphasis is mine). The environment hasn't changed, but there has been a marked shift of gender in positions of responsibility. Problems remain the same, but we have definitely seen a passing of the "old boys' club."-Richard M. Dougherty, Pro- fessor in the School of Information and Library Studies at the University of Michigan, Ann Arbor, Michigan 48109-1092.

"The Changing Role of Directors of University Libraries"' by Arthur M. McAnally and Robert B. Downs appeared in College \& Research Libraries 34, no.2:103-25 (March 1973). $-E d$.

\section{TH ANNIVERSARY YEAR: 1939-1989 \\ IN JULY COLLEGE \& RESEARCH LIBRARIES}

\section{Guest Editorial}

by Richard D. Johnson, former editor

Foundations of Academic Librarianship

by Michael Buckland

Technology and the Future of Libraries

by Susan K. Martin

Research Patterns and Research Libraries: What Should Change?

by Peter S. Graham

The Censorship Phenomenon in College and Research Libraries: An Investigation of the

Canadian Prairie Provinces, 1980-1985

by Alvin M. Schrader, Margaret Herring, and Catriona de Scossa

Genevieve Walton and Library Instruction at the Michigan State Normal College

by Clare Beck 